p-ISSN 1693-1246

e-ISSN 2355-3812

January 2017
Jurnal Pendidikan Fisika Indonesia 13 (1) (2017) 59-70

DOI: 10.15294/jpfi.v13i1.7822 http://journal.unnes.ac.id/nju/index.php/jpfi

\title{
TSUNAMI-MAGNETIC SIGNALS AND MAGNETIC ANOMALY GENERATED BY TSUNAMI WAVE PROPAGATION AT OPEN SEAS
}

\author{
T. Prastowo ${ }^{1,2 *}$, L. Cholifah ${ }^{1}$, L. O. Ngkoimani ${ }^{3}$, L. O. Safiuddin ${ }^{3}$ \\ ${ }^{1}$ Jurusan Fisika, FMIPA, Universitas Negeri Surabaya, Indonesia \\ ${ }^{2}$ Pusat Studi IImu Bumi, FMIPA, Universitas Negeri Surabaya, Indonesia \\ ${ }^{3}$ Jurusan Fisika, FMIPA, Universitas Halu Oleo, Kendari, Indonesia
}

Received: 20 July 2016. Accepted: 30 August 2016. Published: January 2017

\begin{abstract}
This research examines the generation of tsunami-induced magnetic signals, where local magnetic anomaly were measured as variations in the vertical $b_{z}$ and horizontal $b_{H}$ components of the secondary field. The maximum amplitudes of $b_{\mathrm{z}}$ and $b_{\mathrm{H}}$ were analytically estimated and compared to magnetogram provided by INTERMAGNET and BCMT for the 2010 Chilean, the 2011 Tohoku, the 2010 Mentawai and the 2004 Aceh tsunamis. For the first two cases, frozen-flux theory was used to estimate $b_{\mathrm{z}}$ and $b_{\mathrm{H}}$ where the phase lag between $b_{\mathrm{z}}$ and $b_{\mathrm{H}}$ was $\pi / 2$, relevant to time interval of $T / 4$ between the two signals. For the Mentawai case, oceanic diffusion was unignored and $b_{z}$ significantly deviated from that calculated using the theory. However, the data from Mentawai where $b_{\mathrm{z}} \leq 2 \mathrm{nT}$ were in good agreement with $b_{\mathrm{z}}$ generated by large tsunamis occurring in regions near the equator and with magnetogram from the Aceh event.
\end{abstract}

\section{ABSTRAK}

Penelitian ini mempelajari pembangkitan sinyal magnetik akibat perambatan tsunami. Gangguan fisis pada permukaan laut menyebabkan anomali magnetik yang terukur sebagai variasi komponen vertikal $b_{\mathrm{z}}$ dan horisontal $b_{H}$ medan sekunder. Amplitudo maksimum $b_{z}$ dan $b_{H}$ dihitung secara analitik dan dibandingkan dengan magnetogram dari INTERMAGNET dan BCMT untuk tsunami Chili 2010, Tohoku 2011, Mentawai 2010 dan Aceh 2004. Untuk kasus Chili 2010 dan Tohoku 2011, pendekatan frozen-flux secara efektif digunakan untuk estimasi $b_{z}$ dan $b_{H}$ di mana beda fase antara $b_{z}$ dan $b_{H}$ diprediksi $\pi / 2$ yang setara dengan selang waktu T/4 antara kedua sinyal magnetik tersebut. Untuk kasus Mentawai 2010, difusi air laut tidak bisa diabaikan sehingga pendekatan frozen-flux menyimpang signifikan. Namun demikian, data kasus Mentawai 2010 di mana diperoleh $b_{z} \leq 2 \mathrm{nT}$ sesuai dengan estimasi analitik amplitudo maksimum $b_{z}$ yang dibangkitkan oleh tsunami besar di wilayah ekuator yang ternyata juga sesuai dengan data magnetogram kasus Aceh 2004.

(C) 2017 Jurusan Fisika FMIPA UNNES Semarang

Keywords: magnetic anomaly; secondary field; frozen-flux theory; magnetogram

\section{INTRODUCTION}

This study examines tsunami-generated magnetic signals in the context of ocean dynamo effects, where the movement of electrically conducting seawater across the ambient geomagnetic field induces secondary magnetic fields (Tyler, 2005). Such perturbations on the sea surface produce local anomaly with respect

*Correspondence Address:

Kampus Unesa Ketintang, Surabaya 60231

E-mail: prastowo.tjipto@gmail.com to the Earth's magnetic field, which is measured as the vertical and horizontal components of the secondary field. Although the maximum amplitude of the local anomaly is relatively small compared to the main field, it can still be detected by sensitive instrument (Manoj, Maus, \& Chulliat, 2011; Ichihara, Hamano, Baba, \& Kasaya, 2013; Minami \& Toh, 2013; Sugioka et al., 2014). The maximum amplitude is possibly determined by either analytical estimate or visual inspection upon magnetogram obtained from a global magnetic network of International 
Real-time Magnetic Observatory Network (INTERMAGNET) as reported by Klausner, Domingues, Mendes, \& Papa (2011) and Bureau Central de Magnetisme Terrestre (BCMT) as used by Wang \& Liu (2013). Similarities found in the vertical and horizontal components of the tsunami-magnetic signals between analytical estimate and visual inspection on magnetogram provided by the two global institutions are tested for several cases of large tsunamis.

Recent studies (e.g., Tatehata, Ichihara, \& Hamano, 2015) relevant to the generation of magnetic signals and local magnetic anomaly due to tsunami wave propagation have utilized numerical simulation to better understand mechanisms of production and variation of the secondary field. Other studies (e.g. Minami, Toh, \& Tyler, 2015) have also been based on computational work examining effects of seadepth parameter on tsunami wave propagation characteristic at open seas and determine whether advection or diffusion is the dominant physical process in a particular area in the ocean. As evaluated by Klausner, Kherani, \& Muella (2016), a combined work of both computational techniques and field observations for determining the vertical component $b_{z}$ of tsunami-induced signals revealed the same results obtained for separate considerations of nearand far-field distances from a tsunami source.

Minami et al. (2015) discussed the roles of ocean depth $h$ in terms of a functional relationship between the external parameter (ocean diffusivity $\kappa$ ) and internal parameters (tsunami phase speed $c$ and the complex speed of ocean waves $c_{\mathrm{s}}$ ). By adopting ideas of Tyler (2005) and using research findings of Minami et al. (2015), we examine the dependence of local magnetic disturbance $b_{z} / F_{z}$ where $F_{z}$ denotes the vertical component of the main, Earth's magnetic field upon two dimensionless physical parameters, namely: $h / L$ where $L=2.53 \mathrm{~km}$ is the characteristic lengthscale (Minami et al., 2015) and $c / c_{\mathrm{s}}$ where $c_{\mathrm{s}}$ is defined as $c_{\mathrm{s}}=c+\mathrm{i} c_{\mathrm{d}}$ with $c_{d}$ is the rate of oceanic diffusion process (Tyler, 2001).

In this study, four large tsunami occurrences caused by earthquakes with magnitudes of $M_{w} \geq 7.8$ are separately examined and discussed, namely: the 2010 Chilean and the 2011 Tohoku events, where advection dominates over diffusion, and the 2010 Mentawai and the 2004 Aceh tsunamis, where oceanic diffusion cannot be ignored. Discussion for all cases focuses on the roles of important parameters $h / L$ and $c / c_{s}$ for use in determining a proper formula to accurately estimate the vertical and horizontal signals of the tsunami-induced field.

As reported by Satriano, Wu, Zollo, \& Kanamori (2011) and Satake (2014) in terms of concepts and methods of earth-related disaster risk reduction (for example, earthquakes and tsunamis), monitoring of tsunami-generated magnetic signals and the corresponding magnetic anomaly in the present study could thus be an alternative method for the development of a tsunami early warning system. Therefore, this research is expected to give shed light on researchers working on a similar subject and may then complete the existing method of seismic monitoring for tsunami early warning, such as the Indonesian Tsunami Early Warning System (Ina-TEWS) organized by the Indonesian Agency for Geophysics, Climatology, and Meteorology (BMKG). In addition, mechanisms of the generation of tsunami-magnetic signals and magnetic anomaly would be useful for enriched physics teaching materials in schools and universities. This is made possible because basic physic principles of such a phenomenon are derived from a set of Maxwell's equations, including the concept of electromagnetic induction widely known as Faraday and Biot-Savart laws, and Ohm's law for a moving conductor across magnetic lines of force.

\section{METHOD}

The governing equation required for examining fundamental mechanisms of the generation of tsunami-magnetic signals and magnetic anomaly in the oceans is as follows,

$\partial_{\mathrm{t}} b_{\mathrm{z}}=-\nabla_{\mathrm{H}} \cdot\left(F_{\mathrm{z}} \mathbf{u}_{\mathrm{H}}\right)+\kappa \nabla^{2} b_{\mathrm{z}}$

which is commonly known as the electromagnetic induction equation (Tyler, 2005; Ichihara et al., 2013; Sugioka et al., 2014; Minami et al., 2015). The left-hand side of equation (1) describes time evolution of the vertical component $b_{z}$ of the secondary field. The first term of the right-hand side denotes secondary field production by fluid flow of electrically conducting seawater (horizontal advection) while the second term represents contra-production of the secondary field by ocean local circulation (vertical diffusion).

Tyler (2005) evaluated the relative importance of each term on the right-hand side in equation (1) and reported that the ratio of local magnetic disturbance relative to the main geomagnetic field $b_{z} / F_{z}$ is proportional to the ratio of local perturbation in the sea surface elevation relative to the ocean depth $\eta / h$. In this con- 
text, $\eta$ is the maximum vertical displacement of the sea surface owing to tsunami propagation. This idea was adopted and then further developed by Ichihara et al. (2013), Sugioka et al. (2014) and Minami et al. (2015) to derive equations necessary for estimating both the vertical $b_{\mathrm{z}}$ and horizontal $b_{\mathrm{H}}$ components of the tsunami-induced field. When oceanic diffusion can be neglected or in other words, horizontal advection dominates over vertical diffusion ( $c$ l $\left.c_{\mathrm{s}} \approx 1\right)$, it is true that

$b_{z} / F_{z}=\eta / h$

which is well known as frozen-flux approximation, commonly used for analytical estimate of $b_{z}$ given that the other three variables in equation (2) are known. The horizontal component $b_{H}$ of the induced field is then calculated from

$b_{\mathrm{H}}=\mathrm{i} b_{\mathrm{z}}$

which clearly indicates a phase difference between vertical and horizontal tsunamimagnetic signals.

Minami et al. (2015) found diffusion effects unignorable, particularly in parts of the ocean where $h / L<2.0$ such that equation (2) becomes

$b_{\mathrm{z}} / F_{\mathrm{z}}=c / c_{\mathrm{s}} \times \eta / h$

The rate $c_{d}$ of diffusion process at seas is defined as $c_{d}=2 \kappa / h$ and the phase speed $c$ of a tsunami wave is written as $c=(\mathrm{g} h)^{1 / 2}$ where $\mathrm{g}$ is the gravitational acceleration.

Equation (4) shows that the ratio of $b_{z} / F_{z}$ depends upon the ocean depth $h$ and is implicitly determined by two physical processes in the oceans, namely advection process represented by $c$ and diffusion process denoted by $c_{\mathrm{d}}$ in terms of $c / c_{\mathrm{s}}$. This parameter plays a role in determining which process is dominant over the other in the oceans. When $c / c_{\mathrm{s}} \approx 1$ is satisfied, frozen-flux approximation holds and when $c / c_{\mathrm{s}}<1$, frozen-flux approximation gives estimate of $b_{z}$ that significantly deviates from the expected value.

In line with zonal divisions at which a particular process is dominant in the oceans, Minami et al. (2015) proposed that oceanic zones are divided into regimes based on the ratio of $h / L$ where $L$ is defined as $L=\left(2 \kappa / \mathrm{g}^{1 / 2}\right)^{2 / 3}=2.53$ $\mathrm{km}$. Considering this, three dynamic regimes are as follows: (1) $0 \leq h / L \leq 0.5$ where diffusion is adequately strong; (2) $0.5 \leq h / L \leq 2.0$ where diffusion and advection are in balance; and (3) $h / L \geq 2.0$ where advection dominates over diffusion.

The methods including procedures and steps used in the current study involved data inputs, estimation processes, and outputs. All numerical values for the geomagnetic field $F_{z}$ were obtained for free from www.ngdc.noaa. gov/IAGA/vmod/ (International Association of Geomagnetism and Aeronomy [IAGA], 2016) in the form of geomagnetic coefficients issued for the 12th Generation of International Geomagnetic Reference Field (IGRF), numerical data for the global bathymetri of sea depth $h$ were also obtained for free at www.ngdc.noaa.gov/ $\mathrm{mgg} / \mathrm{global} / \mathrm{relief} / \mathrm{ETOPO} 1 /$ (National Geophysical Data Center [NGDC], 2016), numerical data for maximum amplitudes of the sea surface elevation $\eta$ for four large tsunamis, namely: the 2010 Chilean, the 2011 Tohoku, the 2010 Mentawai, and the 2004 Aceh were also freely available at www.ngdc.noaa.gov (National Oceanic and Atmospheric Administration [NOAA], 2016). For comparison, careful visual inspection upon magnetogram freely accessible at www.intermagnet.org (INTERMAGNET, 2016) and www.bcmt.fr (BCMT, 2016) was then performed.

Analytical estimates of $b_{z}$ and $b_{H}$ have used equations (2) and (3) for tsunamis triggered by large earthquakes, that is, the 2010 Chilean and the 2011 Tohoku events as the two events satisfy criteria for frozen-flux approximation. For the 2010 Mentawai tsunami, a number of field data were consistent with advection case requirement $\left(c / c_{s} \approx 1\right.$ and $h / L \geq$ 2.0) where frozen-flux approximation remained effetive, and other data records were partially at a regime where oceanic diffusion effects started to influence (intermediate regime) and the rest were classified into the dominant diffusion regime. Therefore, estimate of $b_{z}$ for the Mentawai tsunami used equation (4) but values of $b_{\mathrm{H}}$ for the same case were still estimated using equation (3). The 2004 Aceh tsunami is here discussed in comparison with that of the Mentawai. Outputs of all cases considered in this study are values of $b_{\mathrm{Z}}$ and $b_{\mathrm{H}}$ obtained from analytical estimates for cases either with frozen-flux or with no frozen-flux approximation and visual estimates through inspection on either magnetogram provided by INTERMAGNET and BCMT or relevant graphs of magnetic variations recorded by magnetic instrument deployed at the sea floor, such as Ocean Bottom Electromagnetometer (OBEM).

\section{RESULTS AND DISCUSSIONS}

Two large tsunamis firstly discussed are the Chilean event that occurred on 27 February 
2010 with the epicenter is located at $36.1^{\circ} \mathrm{S}$ and $72.6^{\circ} \mathrm{W}$, tsunami origin time (OT) at 06:44 Universal Time Coordinates (UTC), and magnitude of $M_{w} 8.8$ and the other that occurred in Tohoku on 11 March 2011 with the epicenter at $38.3^{\circ} \mathrm{N}$ and $142.4^{\circ} \mathrm{E}$, tsunami OT at 05:51 UTC, and magnitude of $M_{\mathrm{w}}$ 8.9. Table 1 contains complete data listing names of magnetic station with their corresponding geographical positions, numerical values of $F_{z}, \eta$ and $h$ obtained from relevant sites previously stated, and the vertical component $b_{\mathrm{z}}$ calculated using equation (2). IPM, PPT, and KAK are names of magnetic station while B14 (one of OBEM as used by Ichihara et al., 2013) is sensitive instrument deployed at the sea floor having the same function as magnetic station to monitor electromagnetic signals induced by tsunami waves.

Values for $b_{z}$ in Table 1 are tested by recalculating them with respect to the effects of oceanic diffusion (see corresponding values in Table 2). Indeed, $b_{z}$ is recalculated using equation (4) in which some physical quantities needed are as follows: $\kappa=(\mu \sigma)^{-1}$ with $\mu \approx \mu_{\mathrm{o}}=4 \pi$ $\times 10^{-7} \mathrm{WbA}^{-1} \mathrm{~m}^{-1}$ (ocean magnetic permeability), $\sigma \approx 4 \mathrm{Sm}^{-1}$ (conductivity of seawater) and the complex speed of ocean waves $C_{\mathrm{s}}$ calculated from $c_{\mathrm{s}}=\left(c^{2}+c_{\mathrm{d}}^{2}\right)^{1 / 2}$ where $c$ and $c_{\mathrm{d}}$ are previously defined.

Table 2 provides recalculated values for $b_{\mathrm{z}}$ using equation (4), where the results differ by $\leq 7 \%$ from those calculated using equation (2). This discrepancy is considered insignificant hence frozen-flux approximation remains valid. This argument is supported by values listed in columns 4 and 8 in Table 2 , where $h / L \geq 2.0$ and $c / c_{\mathrm{s}} \approx 1$ are found in all monitoring stations for the two events. With respect to small perturbations of $b_{z}$ from its maximum amplitude, frozenflux theory is proved to be reliable and effective for use to estimate $b_{z}$ accurately enough, in particular when diffucion effects are ignorable.

As previously written, estimates of $b_{z}$ using both equations (2) and (4) are compared with records of magnetogram provided by the global network of INTERMAGNET and BCMT. Graphical magnetogram indicates that for the 2010 Chilean event there is a periodic signal of magnetic variations observed and measured by instrument at IPM seen in Figure 1 for magnetogram from INTERMAGNET and in Figure 2 for magnetogram from BCMT.

Figure 1 clearly shows effects of local disturbances on the sea surface due to earthquake with large magnitude that occurred off the coast of Chili, where the disturbances generated a giant tsunami wave propagating across the Pacific and then arriving at IPM $3500 \mathrm{~km}$ away from the epicenter. In turn, magnetic perturbations due to tsunami wave propagation were well recorded as the periodic signal $b_{z}$ of the secondary field (denoted by three redcircles in the $Z$ component of INTERMAGNET magnetogram). The periodic signal is obviously observed to occur around 11:45 UTC and provides a convincing clue for the magnetic anomaly with the mean value of the amplitude is best estimated at about $0.47 \mathrm{nT}$.

For comparison, Figure 2 provides magnetogram from BCMT for the same event. The periodic tsunami-magnetic signal was also re-

Table 1. Data for the 2010 Chilean and the 2011 Tohoku events with $b_{z}$ is calculated using equation (2).

\begin{tabular}{cccccccc}
\hline $\begin{array}{c}\text { Tsunami } \\
\text { Event }\end{array}$ & $\begin{array}{c}\text { Magnetic } \\
\text { Station }\end{array}$ & $\begin{array}{c}\text { Latitude } \\
\text { Position }\end{array}$ & $\begin{array}{c}\text { Longitude } \\
\text { Position }\end{array}$ & $\begin{array}{c}F_{\mathrm{z}} \\
(\mathrm{nT})\end{array}$ & $\begin{array}{c}\eta \\
(\mathrm{m})\end{array}$ & $\begin{array}{c}h \\
(\mathrm{~m})\end{array}$ & $\begin{array}{c}b_{\mathrm{z}} \\
(\mathrm{nT})\end{array}$ \\
\hline 2010 Chilean & $\mathrm{IPM}$ & $27.17^{\circ} \mathrm{S}$ & $109.41^{\circ} \mathrm{W}$ & 19019.6 & 0.15 & 6933 & 0.41 \\
& $\mathrm{PPT}$ & $17.57^{\circ} \mathrm{S}$ & $149.57^{\circ} \mathrm{W}$ & 18886.0 & 0.12 & 5085 & 0.45 \\
\multirow{2}{*}{2011 Tohoku } & $\mathrm{B} 14$ & $39.03^{\circ} \mathrm{N}$ & $144.48^{\circ} \mathrm{E}$ & 37271.6 & 2.35 & 5830 & 15.02 \\
& KAK & $36.23^{\circ} \mathrm{N}$ & $140.18^{\circ} \mathrm{E}$ & 35619.2 & 4.50 & 10272 & 15.60 \\
\hline
\end{tabular}

Table 2. Data for the 2010 Chilean and the 2011 Tohoku events with $b_{z}$ is calculated using equation (4).

\begin{tabular}{ccccccccc}
\hline Tsunami Event & $\begin{array}{c}\text { Magnetic } \\
\text { Station }\end{array}$ & $\begin{array}{c}h \\
(\mathrm{~m})\end{array}$ & $h / L$ & $\begin{array}{c}c \\
\left(\mathrm{~ms}^{-1}\right)\end{array}$ & $\begin{array}{c}c_{\mathrm{d}} \\
\left(\mathrm{ms}^{-1}\right)\end{array}$ & $\begin{array}{c}c_{\mathrm{s}} \\
\left(\mathrm{ms}^{-1}\right)\end{array}$ & $\begin{array}{c}c / c_{\mathrm{s}} \\
\text { 2010 Chilean }\end{array}$ & $\begin{array}{c}b_{\mathrm{z}} \\
(\mathrm{nT})\end{array}$ \\
& PPT & 6933 & 2.7 & 260.7 & 57.4 & 266.9 & 0.98 & 0.40 \\
\multirow{2}{*}{2011 Tohoku } & B14 & 5885 & 2.0 & 223.2 & 78.3 & 236.6 & 0.94 & 0.42 \\
& KAK & 10272 & 4.1 & 317.3 & 38.8 & 319.6 & 0.99 & 15.49 \\
\hline
\end{tabular}




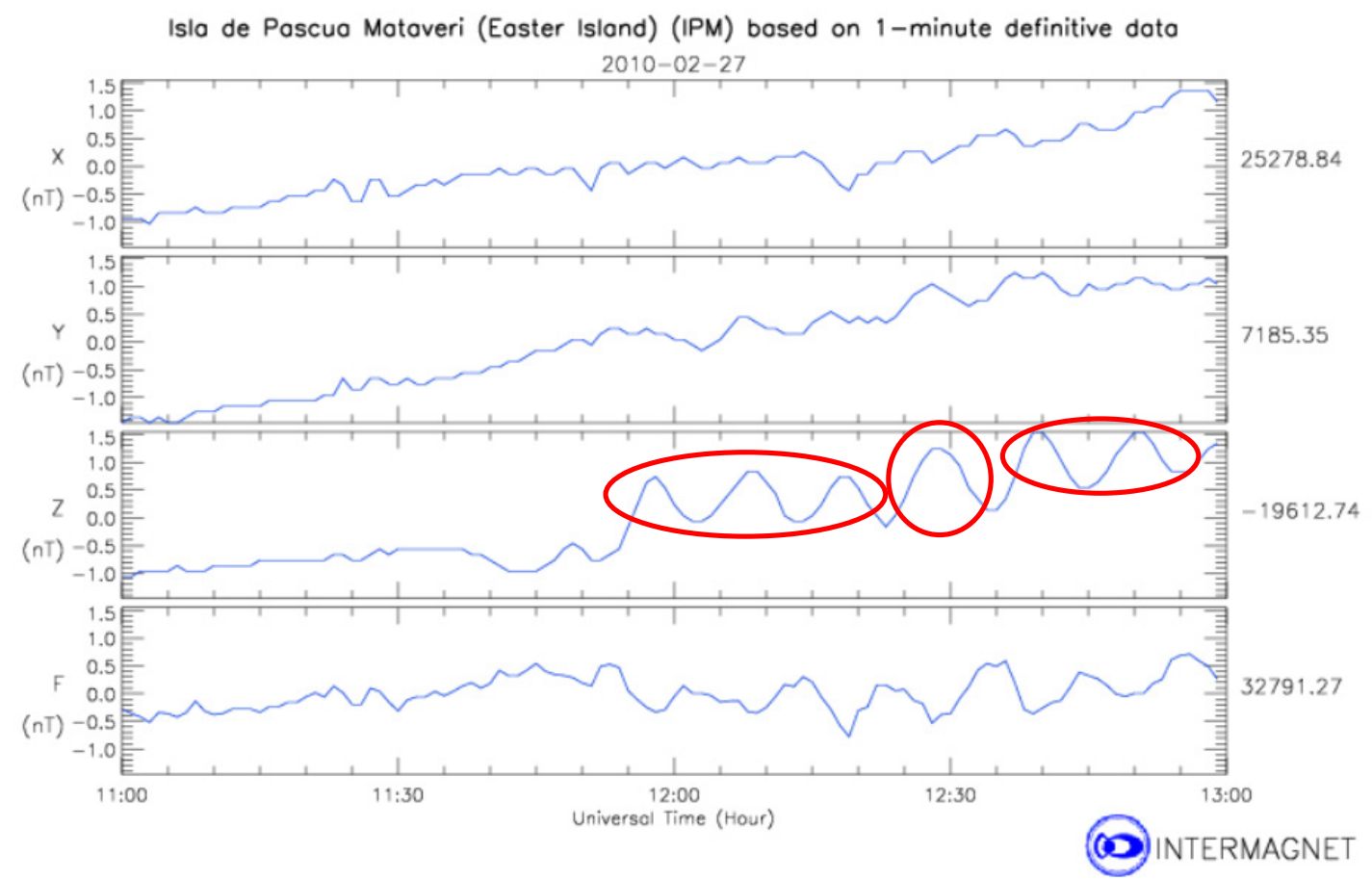

Figure 1. Magnetogram from INTERMAGNET for the 2010 Chilean tsunami occurrence recorded at IPM (3500 km away from the epicenter) after 5-hours travelling from the epicenter towards IPM.

corded at IPM run by BCMT, where the magnetic anomaly started to observe at 11:45 UTC with the mean amplitude of about $0.48 \mathrm{nT}$. This value is considered insignificant difference from that given by INTERMAGNET.

Data for magnetogram from both INTERMAGNET and BCMT are also in good agreement with variations in hydrostatic pressure at the ocean bottom measured by OBEM close to IPM location, where maximum hydrostatic pressure variation is estimated to be equal to $b_{\mathrm{z}} \approx 0.50 \mathrm{nT}$ (Sugioka et al., 2014). The amplitude of the signal is consistent with peak-topeak variation of $b_{z}$ at about $1.0 \mathrm{nT}$ suggested by Manoj et al. (2011) for the same tsunami. A slight difference in the results between analytical estimates and visual inspection using magnetogram is attributed to inaccuracy of ocean depth measurements of $h$ obtained from a world map of ocean topography from global bathymetri data.

Different from the 2010 Chilean case in which tsunami propagation was characterized by periodic signals, a giant tsunami triggered by the 2011 Tohoku tsunamigenic earthquake demonstrated a traveling solitary wave. This is seen in Figure 3 within time interval 6:45-7:45 UTC, where a significant increase in the variation of the vertical signal is estimated to be $b_{z}$ $\approx 15.8 \mathrm{nT}$ (red circle in Figure 3). This is in good agreement with theoretical prediction for the magnetic anomaly of $b_{z}$ based on frozen-flux approximation, which gives $b_{\mathrm{z}} \approx 15.6 \mathrm{nT}$ (KAK in Table 1).

Analytical estimate dan visual inspection upon relevant magnetogram for the 2011 Tohoku event are consistent with field observations made by Ichihara et al. (2013) using magnetic instrument (OBEM) placed at the sea floor. They found that the vertical component $b_{z}$ of the tsunami-magnetic signals varied in the range $b_{\mathrm{z}} \approx 12-19 \mathrm{nT}$ with the mean value of $b_{\mathrm{z}} \approx$ $15.5 \mathrm{nT}$ (see Figure 4).

In addition to good agreement with relevant previous work (Ichihara et al., 2013; Zhang, Baba, Liang, Shimizu, \& Utada, 2014), the research results in this study are also confirmed by the findings of Minami \& Toh (2013), reporting impulsive signals of the vertical component variation $b_{\mathrm{z}}$ with the amplitude of about $3 \mathrm{nT}$. The signal was detected by electromagnetometer sinking at the sea floor in the NorthWest Pacific (NWP) site $1500 \mathrm{~km}$ away from the epicenter. The earthquake induced a devastating tsunami, hitting areas off the east coast of Tohoku on 11 March 2011.

Significant discrepancies in $b_{z}$ between the value of $b_{z}=3 \mathrm{nT}$ (Minami \& Toh, 2013) and the ones of $b_{z}=15.6 \mathrm{nT}$ (analytical estimate based on frozen-flux approximation with the 


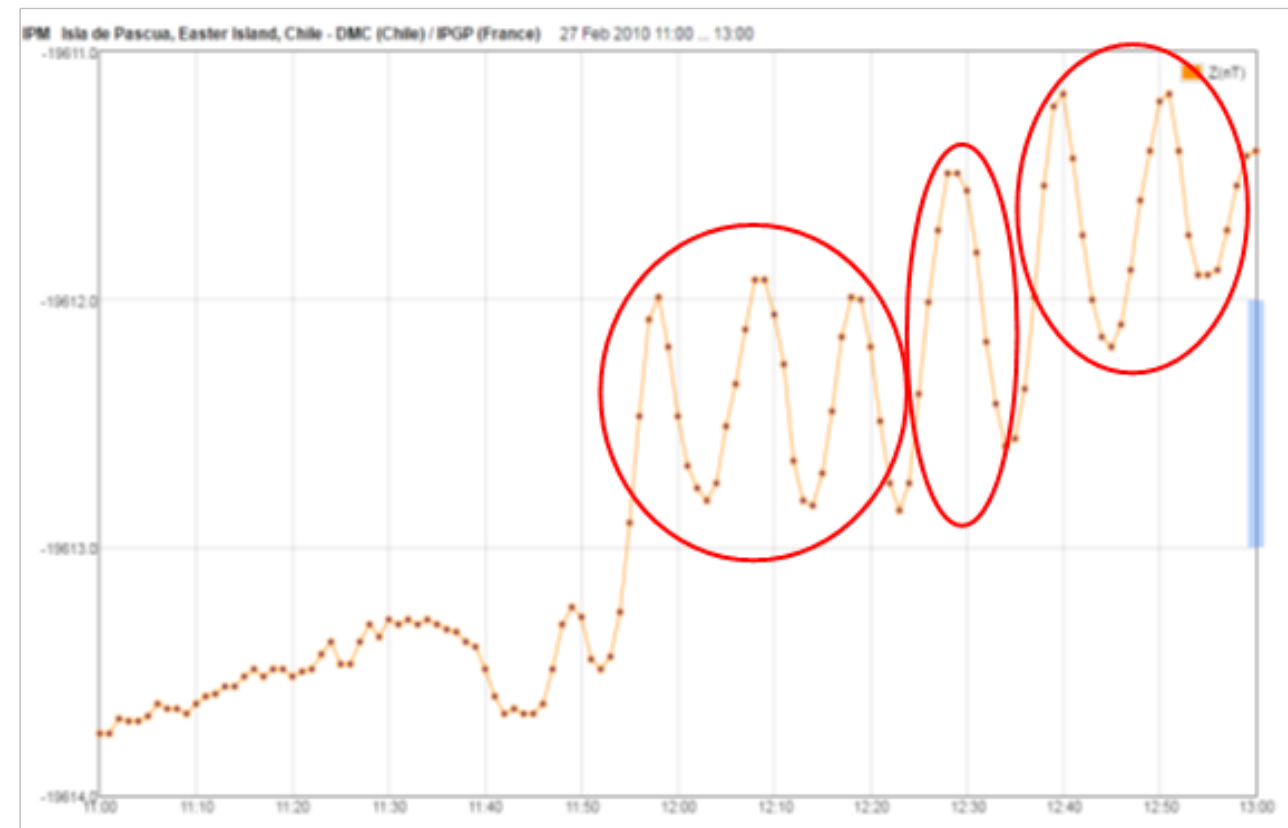

Figure 2. Magnetogram from BCMT for the 2010 Chilean tsunami occurrence recorded at IPM (3500 km away from the epicenter) after 5-hours travelling from the epicenter towards IPM.

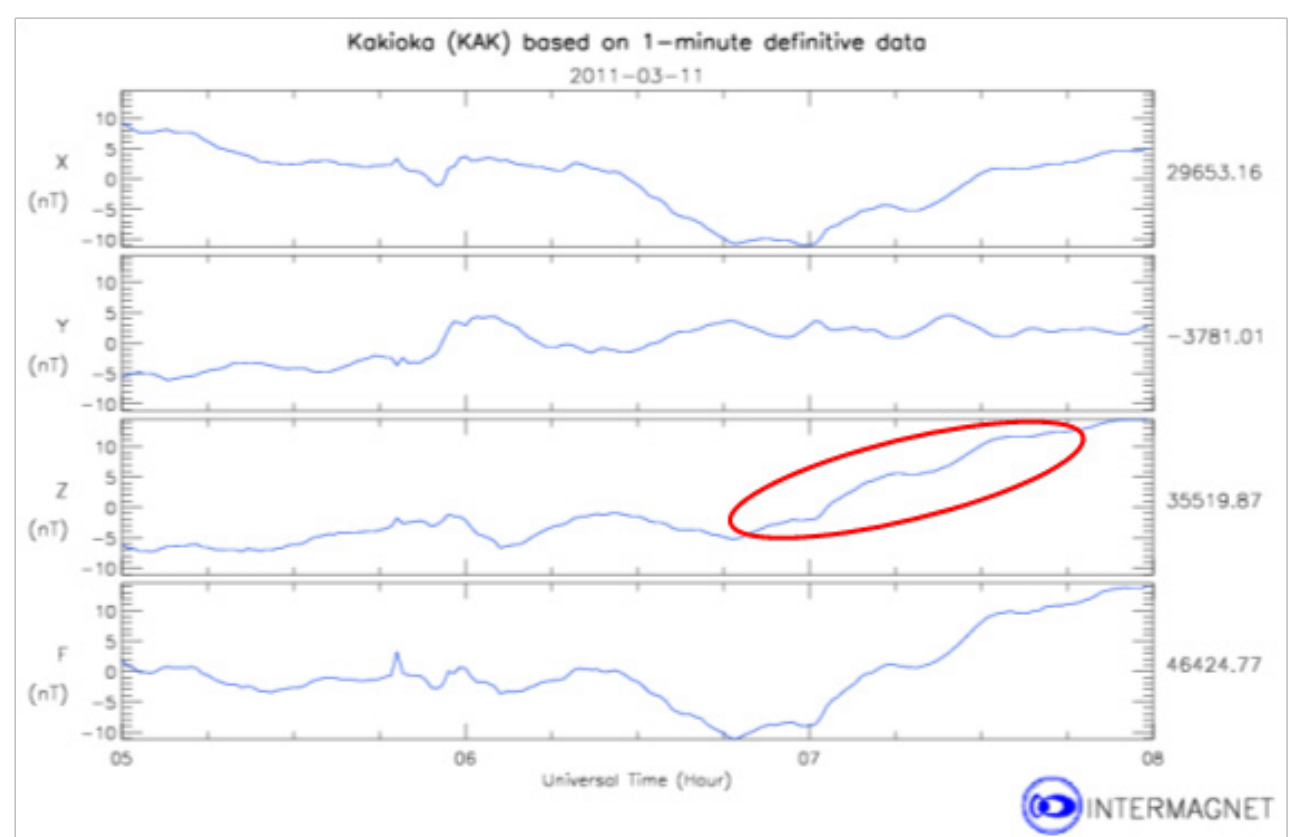

Figure 3. Magnetogram from INTERMAGNET for the 2011 Tohoku tsunami recorded at KAK (320 $\mathrm{km}$ away from the epicenter) within 1-hour travelling from the epicenter.

data from stasiun KAK) and $b_{\mathrm{z}}=15.8 \mathrm{nT}$ (visual estimate based on magnetogram from INTERMAGNET) are due to the difference in observational locations. A simple calculation performed with respect to the geographical positions of magnetic instrument at the NWP site (Minami \& Toh, 2013), B14 (Ichihara et al., 2013), and KAK as well yields the mean value of $b_{z} \approx 2.9$ nT for the 2011 Tohoku event, consistent with the result of Minami \& Toh (2013).

Figure 4 proves the maximum amplitude achieved for real time-varying of the vertical component $b_{z}$ to be proportional to its corresponding sea surface elevation $\eta$ monitored by a tsunami-gauge meter in the west Pacific (managed by NOAA) near the earthquake epicenter that generated Tohoku catastrophy. The proportionality between the two variables sup- 
ports both theoretical estimates of $b_{z}$ based on either frozen-flux approximation as predicted by equation (2) or calculation with the inclusion of diffusion effects as given by equation (4). The horizontal axis measured in minutes in Figure 4 below shows running time measured from earthquake OT. A high level of similarity is found in the variation of $b_{z}$ between simulation on the basis of electromagnetic induction concept and in situ observations, particularly at tsunami onset time. This is clearly seen when the amplitude of the impulsive tsunami signal achieves its maximum value as shown by the red circle in Figure 4.

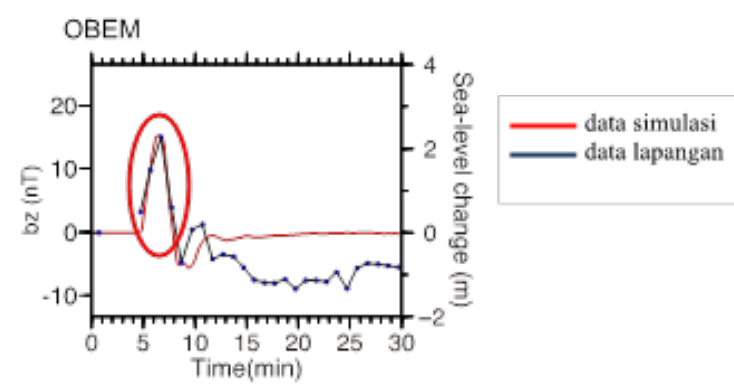

Figure 4. Time-varying of the vertical component $b_{z}$ of the tsunami-magnetic field and its corresponding sea level change $\eta$ from the 2011 Tohoku event recorded by B14, one of OBEM at the sea floor (250 km away from the epicenter), where $b_{\mathrm{z}} \approx 15.5 \mathrm{nT}$ (taken from Figure 4, Ichihara et al., 2013).

Theory of motional induction at seas describes not only the change in the vertical component $b_{\mathrm{z}}$ of the secondary magnetic signals relative to the primary geomagnetic field $F_{z}$ but also the variations in the horizontal component $b_{H}$ due to tsunami. In the context of timevarying of $b_{z}$ two equations generally needed to estimate $b_{z}$ are the one given by equation (2) used when horizontal advection is assumed to be the dominant process, widely known as frozen-flux approximation and the other given by equation (4) used when diffusion is somewhat important. In the context of time-varying of $b_{H}$ the only formula for use in determining its maximum amplitude is given by equation (3) that holds for cases both with frozen-flux and with no frozen-flux approximation.

The followings are simple analyses related to equation (3). Firstly, replacing $\mathrm{i}$ with $\mathrm{i}=$ $\exp (i \pi / 2)$ and then writing the dependence of both $b_{\mathrm{z}}$ and $b_{\mathrm{H}}$ upon time $t$ as

$b_{\mathrm{z}}=b_{\mathrm{oz}} \exp (-\mathrm{i} \omega t)$

$b_{\mathrm{H}}=b_{\mathrm{oH}} \exp (-\mathrm{i} \omega t)$

where $b_{\mathrm{oz}}$ and $b_{\mathrm{oH}}$ represent maximum amplitudes for the vertical $b_{\mathrm{z}}$ and horizontal $b_{\mathrm{H}}$ components, respectively. Secondly, substituting equations (5) and (6) as well as $\mathrm{i}=\exp$ $(\mathrm{i} \pi / 2)$ into equation (3) yields

$$
b_{\mathrm{oH}} \text { eks }(-\mathrm{i} \omega t)=b_{\mathrm{oz}} \text { eks }\{-\mathrm{i}(\omega t-\pi / 2)\}
$$

Equation (7) clearly shows a phase difference in the tsunami-magnetic signals between $b_{\mathrm{z}}$ and $b_{\mathrm{H}}$, where the horizontal signal $b_{\mathrm{H}}$ leads to the vertical signal $b_{z}$ by $\pi / 2$. As fluctuation of the secondary magnetic field is in the form of harmonic function of period $T$, the phase lag between the two signals is equal to the time interval $T / 4$ required to achieve the maximum amplitude for each signal, with the horizontal component $b_{H}$ achieves its maximum before the vertical component $b_{z}$ does.

Within the context of the above mathematical analyses, $T$ denotes the period of a tsunami wave that could be determined by simple uniform motion of the wave along its path. Some typical parameters needed to estimate $T$ include the ocean depth of $h \sim 5000 \mathrm{~m}=$ $5 \mathrm{~km}$, the tsunami phase speed of $c=(\mathrm{g} h)^{1 / 2}$ $\sim 200 \mathrm{~m} / \mathrm{s}=720 \mathrm{~km} / \mathrm{h}$, and the the tsunami wavelength of $\lambda \sim 120 \mathrm{~km}$. Taking these parameters all together, we have $T \sim 10$ minutes.

Figure 5 gives observational records for the horizontal $b_{\mathrm{H}}$ and vertical $b_{\mathrm{z}}$ of the secondary signals monitored by four magnetic instrument at the sea floor discussed in Zhang et al. (2014). All instrument named NM02, NM04, NM01, and NM05 and positioned at various locations with respect to the epicenter of the earthquake generating the 2011 Tohoku tsunami clearly indicate that the horizontal component $b_{\mathrm{H}}$ (represented by the dominant signal $b_{\mathrm{y}}$ in Figure 5) achieves its first peak before the vertical signal $b_{z}$. The $b_{y}$ signals were respectively recorded at NM02, NM04, NM01, and NM05: 60 minutes, 64.44 minutes, 68.33 minutes, and 72.78 minutes whereas the $b_{z}$ signals were observed at NM02, NM04, NM01, and NM05: 62.78 minutes, 66.67 minutes, 70.56 minutes, and 75.56 minutes, respectively, both records after tsunami onset time at 05:46 UTC. Based on the estimated arrival time difference between $b_{y}$ and $b_{z}$ signals at the accounted four stations (NM02, NM04, NM01, NM05), then the averaged arrival time difference for the two signals $\left(b_{y}\right.$ and $\left.b_{z}\right)$ to achieve their associated peak is about 2.5 minutes, in good agreement with $T / 4$. This gains support from the work of Ichihara et al. (2013) stating that the dominant part of the horizontal component $b_{\mathrm{H}}$ is of $b_{\mathrm{y}}\left(b_{\mathrm{y}}\right.$ signal dominates over $b_{\mathrm{x}}$ signal as $b_{\mathrm{x}}$ signal is relatively weak) for the Tohoku event and that 
the leading signal $b_{\mathrm{y}}$ precedes $b_{\mathrm{z}}$ by $\sim 2$ minutes.

The two large tsunamis, the 2010 Chilean and the 2011 Tohoku events, occurred at places of relatively deep waters with $h \geq 5100$ m such that $h / L \geq 2.0$ because of $L=2.53 \mathrm{~km}$ (Minami et al., 2015). The ratio of $h / L \geq 2.0$ is correlated with $c / c_{s} \approx 1$ (see Table 2). The data provided in Table 2 suggest that the deeper the ocean the larger the ratio of $c / c_{s}$. In other words, horizontal advection is stronger in places where the ocean is adequately deep and dominates over diffusion efects in the deep sea and therefore frozen-flux theory is effective for use to estimate $b_{z}$ in such places. However, the effects of diffusion become unignorable in shallow waters where $h / L \leq 2.0$ (for example, the Indonesian waters). For cases where diffusion effects play a role in the dynamics of tsunamimagnetic signal generation, estimate of $b_{z}$ is performed using equation (4) whereas estimate of $b_{H}$ is still calculated using equation (3).

Table 3 below gives an example of the Mentawai tsunami that occurred on 25 October 2010 with the epicenter is located at $3.48^{\circ} \mathrm{S}$ and $100.14^{\circ} \mathrm{E}$, tsunami OT at 15:00 UTC, and magnitude of $M_{\mathrm{w}} 7.8$, where the depth of observational locations varies from relatively shallow to deep waters.
The data listed in Table 3 clearly show the ratio of $h / L<2.0$ and $c / c_{s}<0.9$ for the first four observational locations. The role of diffusion effects decreases much with increasing both $h / L$ and $c / c_{\text {s }}$ found in deep-sea places. For Cocos Island in the western Australian waters and Enggano in Bengkulu, the dominant process is advection and thus estimates of $b_{z}$ in the two areas utilize the frozen-flux theory as predicted by equation (2) or the incorporation of oceanic diffusion effects into prediction as given by equation (4).

Observational location at Teluk Dalam in which the ratio of $h / L=0.3$ and $c / c_{s}=0.15$ indicates that a strong diffusion process is on duty. This is confirmed by a large deviation of $b_{z}$ at a value of $84 \%$ from its true value based on calculation using equation (4).

Observational locations in Padang, Port Louis, and Rodrigues satisfy $0.5 \leq h / L \leq 2.0$ such that measurements of $b_{z}$ are classified into intermediate regime (Minami et al., 2015). For Rodrigues, $h / L=1.3$ and $c / c_{\mathrm{s}}=0.83$ the calculated value of $b_{z}$ using equation (2) deviates from that when it is calculated using equation (4) by $17 \%$. Such deviation reflects a dynamical balance between advection and diffusion.

The last two locations monitoring the Mentawai case in Table 3 demonstrate the

Table 3. Data for the 2010 Mentawai tsunami with $b_{z}$ is calculated using equation (4).

\begin{tabular}{clccccccc}
\hline $\begin{array}{c}\text { Tsunami } \\
\text { Event }\end{array}$ & $\begin{array}{l}\text { Observation- } \\
\text { al Location }\end{array}$ & $\begin{array}{c}h \\
(\mathrm{~m})\end{array}$ & $h / L$ & $\begin{array}{c}c \\
\left(\mathrm{~ms}^{-1}\right)\end{array}$ & $\begin{array}{c}c_{\mathrm{d}} \\
\left(\mathrm{ms}^{-1}\right)\end{array}$ & $\begin{array}{c}c_{\mathrm{s}} \\
\left(\mathrm{ms}^{-1}\right)\end{array}$ & $c / c_{\mathrm{s}}$ & $\begin{array}{c}b_{\mathrm{z}} \\
(\mathrm{nT})\end{array}$ \\
\cline { 2 - 9 } & Teluk Dalam & 732 & 0.3 & 84.7 & 543.8 & 550.4 & 0.15 & 0.37 \\
\hline \multirow{4}{*}{2010} & Padang & 1882 & 0.7 & 135.8 & 211.5 & 251.4 & 0.54 & 1.67 \\
Mentawai & Port Louis & 2864 & 1.1 & 167.5 & 139.0 & 217.7 & 0.77 & 1.95 \\
& Rodrigues & 3261 & 1.3 & 178.8 & 122.1 & 216.5 & 0.83 & 2.15 \\
& Cocos Island & 6187 & 2.4 & 246.2 & 64.3 & 254.5 & 0.97 & 1.03 \\
& Enggano & 6699 & 2.6 & 256.2 & 59.4 & 263.0 & 0.97 & 0.71 \\
\hline
\end{tabular}

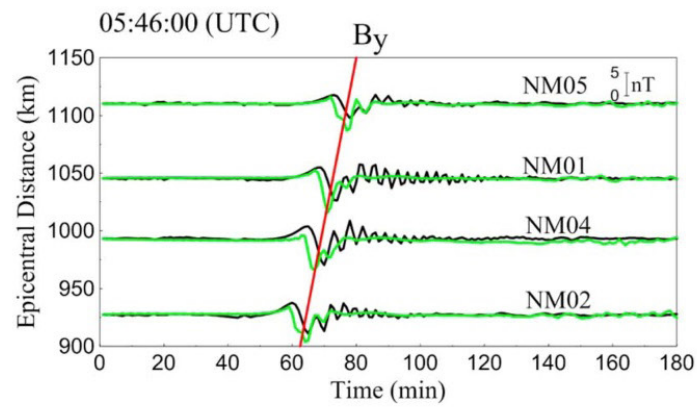

(a)

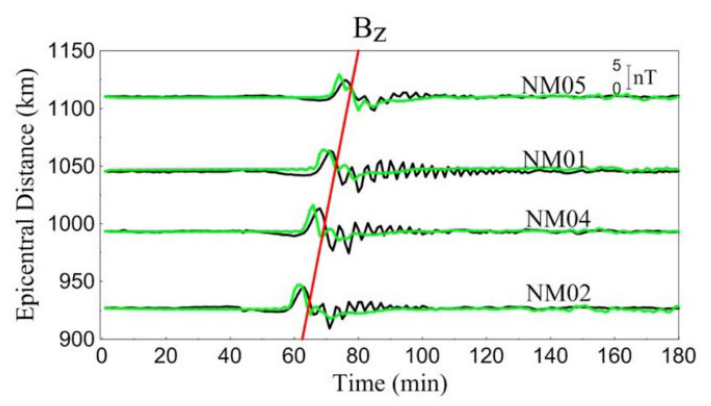

(b)

Figure 5. (a) The $b_{y}$ signal representing the horizontal component $b_{H}$ and (b) the vertical component $b_{z}$ of the secondary magnetic field owing to tsunami for the 2011 Tohoku event recorded by four ocean bottom magnetometers named NM02, NM04, NM01, and NM05 (taken from Figure 1, Zhang et al., 2014). 
dominance of horizontal advection over vertical diffusion as $h / L \geq 2.0$ and $c / c_{s}=0.97$. This confirms that estimate of $b_{z}$ in the two locations was performed using frozen-flux approximation. The use of this approximation results in a small difference, of only $3 \%$, in the calculation of $b_{z}$ between the calculated value given by equation (2) and the one given by (4).

The data for $b_{z}$ listed in Table 3 also show a systematic increase in the magnetic disturbance due to tsunami wave propagation, becoming stronger as it approaches the zonal boundary between diffusion and intermediate regimes, reaching its maximum disturbed condition where $b_{z}$ achieves it maximum value of $2.15 \mathrm{nT}$ observed in Rodrigues, undergoing weakening effects when penetrating into advection regime. This feature is well predicted by Minami et al. (2015).

The results for $b_{z}$ estimates reported in Table 3 vary from $0.37 \mathrm{nT}$ to $2.15 \mathrm{nT}$, consistent with both field measurements and numerical simulations of the vertical component of tsunami -magnetic signals obtained for areas near the equator. Tyler (2005) and Klausner et al. (2011) found a value of $b_{z} \leq 2,5 \mathrm{nT}$ for these areas.

However, the listed data in Table 3 for the 2010 Mentawai event confirm the maximum theoretical prediction for $b_{\mathrm{z}}$ based on frozenflux theory that was proposed by Tyler (2005) after the most devastating tsunami hitting the west coast of Aceh in December 2004. The catastrophy tsunami was difficult to handle because there was no a well-developed, tsunami early warning system employed in the impacted areas, along the shorelines of Sumatranian west coast and surrounding the Indian Ocean. It was surprising that none of the local authority, such as BMKG nor global institutions, such as NGDC, NOAA and the Pacific Tsunami Warning Center (PTWC) managed instrument practically deployed for specific purposes on local deep sea research and regional sea surface monitoring in the Indian Ocean. Therefore, empirical data for local perturbations at the sea surface elevation $\eta$ and ocean depth $h$ are not available in these areas and hence analytical estimates of magnetic anomaly using equations (2), (3), and (4) cannot be performed. Contrary to this, visual estimates through inspection upon magnetogram for the case of Aceh tsunami remain available as given by both INTERMAGNET see in Figure 6 and BCMT seen in Figure 7.

Figure 6 describes local magnetic anomaly caused by earthquake having the hypocenter below the sea surface at depth. The magnitude of the earthquake is of $M_{w} 9.1$ occurring on 26 December 2004 at $3.4^{\circ} \mathrm{N}$ and $95.7^{\circ} \mathrm{E}$, and tsunami OT at 01:18 UTC. The red circle in Figure 6 shows tsunami on-set at 01:15 UTC.

Figure 7 provides magnetogram from BCMT for the same case as that in Figure 6 , where $\mathrm{PHU}$ is located at $21.3^{\circ} \mathrm{N}$ and $105.95^{\circ}$

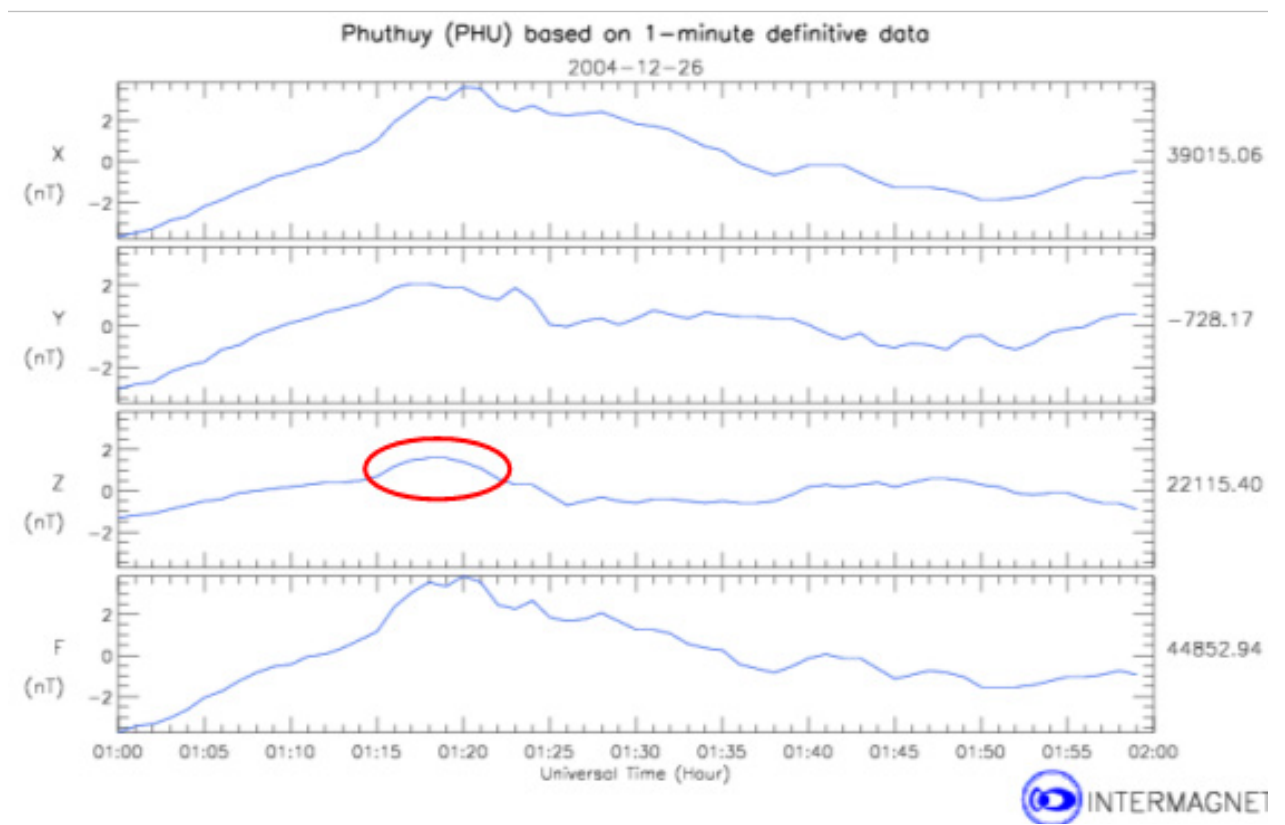

Figure 6. Magnetogram from INTERMAGNET for the 2004 Aceh occurrence recorded at PHU (Vietnam), showing $b_{z} \approx 1.8 \mathrm{nT}$ at the maximum amplitude of the tsunami-magnetic signal achieved. 


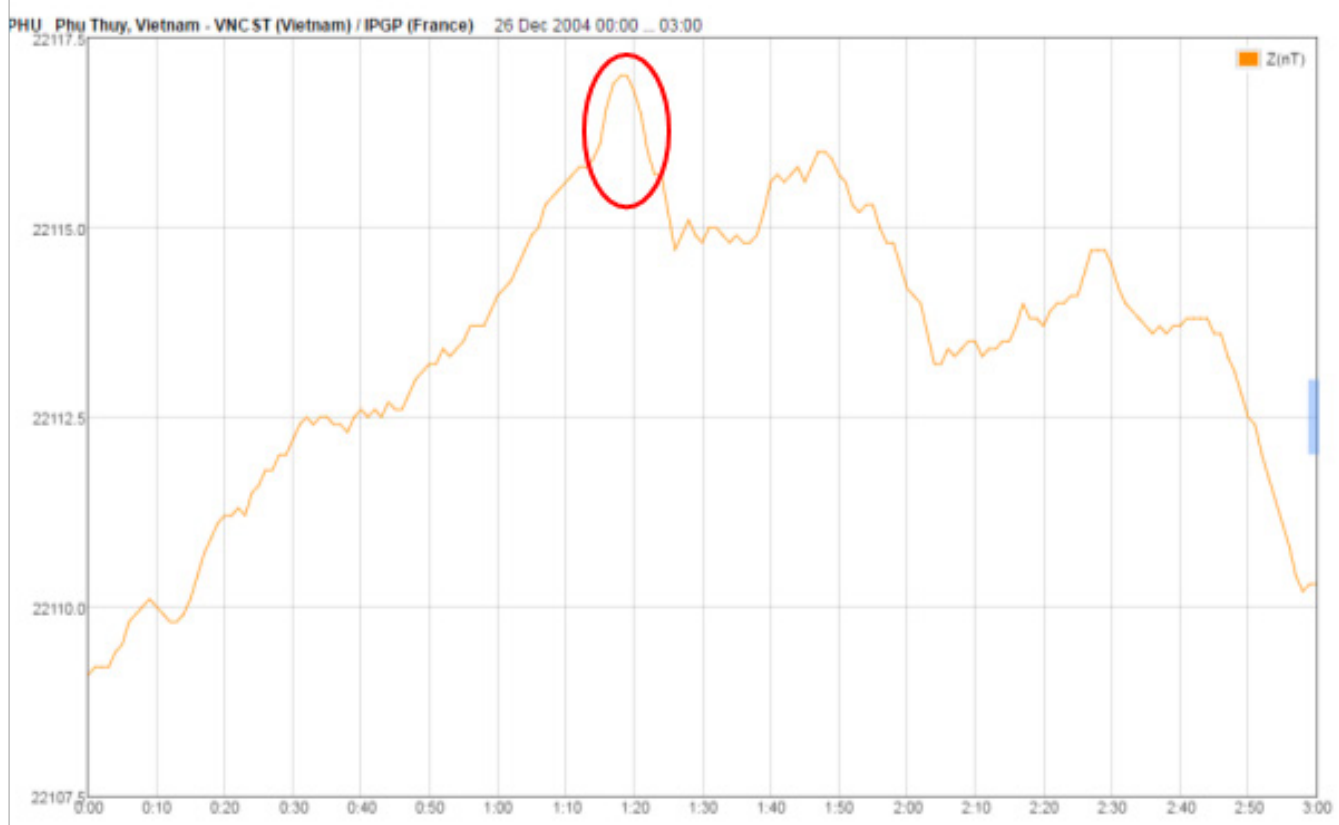

Figure 7. Magnetogram from BCMT for the 2004 Aceh occurrence recorded at PHU (Vietnam), showing $b_{z} \approx 2.0 \mathrm{nT}$ at the maximum amplitude of the tsunami-magnetic signal achieved.

$E$ and confirms that the maximum amplitude of the vertical component $b_{z}$ is found to be $b_{z} \approx$ $2.0 \mathrm{nT}$ (denoted by red circle), which was recorded within time interval 1:13-1:22 UTC, consistent with time interval observed for the same event provided by INTERMAGNET. The data records at $\mathrm{PHU}$ given by instrument managed by INTERMAGNET and BCMT are also in good agreement with magnetogram measured by similar instrument in AAE (Ethiopia) located at $9.02^{\circ} \mathrm{N}$ and $38.77^{\circ} \mathrm{E}$, where $b_{\mathrm{z}} \approx 2.5 \mathrm{nT}$. The measured value of $b_{z} \sim 2 \mathrm{nT}$ obtained from the two stations is supported by the work of Klausner et al. (2011) using wavelet computational techniques.

Having analyzed the generation of secondary magnetic signals and local anomaly in the vertical $b_{\mathrm{z}}$ and horizontal $b_{\mathrm{H}}$ owing to tsunami passages for four large tsunami events, namely: the 2010 Chilean, the 2011 Tohoku, the 2010 Mentawai, and the 2004 Aceh with large, sea-hypocentered earthquakes and magnitudes of $M_{w} \geq 7.8$, some crucial points of views are discussed in the following paragraphs.

Firstly, the intensity of local anomaly signal is relatively small compared to the one produced by the Earth's fluid outer core, termed as the main geomagnetic field (Prastowo \& Jannah, 2015). Therefore, the design and development of sensitive electromagnetic sensors for field monitoring and measurements of magnetic fields induced by ocean flow is a must. This is important because the success of real- time monitoring of any phenomenon in nature generally relies much on instrument accuracy and sensitivity. Hence, the advance of science and modern technology relevant to a particular earth-related disaster, such as tsunamigenic earthquakes and tsunamis, allows us to improve both the quality of measurement facilities for a better early warning system and the effectiveness of an approach to hazard mitigation study (Satriano et al., 2011; Satake, 2014).

Secondly, real-time monitoring of tsunami-magnetic signal and its corresponding local anomaly in the oceans examined in this study can therefore be an alternative method of the existing tsunami early warning system. This existing method has been based on seismic monitoring, for example, instrument for field measurements of seismic activities utilizing Global Positioning System (GPS) to rapid analyses of the earthquake size (Blewitt, Kreemer, Hammond, Plag, \& Stein, 2006). Current studies relying upon seismic signal monitoring has included examination of subsurface seimo-tectonic activities covering areas in Sumatra (Santosa, 2012) and evaluation of accuracy in determination of some earthquake parameters for improvement of Ina-TEWS performance (Madlazim \& Prastowo, 2016). Compared to these studies, the present method used in this study is promising and excellent in the sense that the developed method of tsunami-magnetic signal estimates, as predicted by equations (2) and (4), directly relates to a tsunami parameter, 
that is, $\eta$, representing the maximum vertical sea surface displacement due to the passage of a tsunami wave at open seas. Knowledge of disturbance in the sea surface elevation $\eta$ is required for better prediction of tsunami height (water run-up) when the giant wave approaches shorelines. Hence, this work is also important for hazard mitigation study.

Thirdly, in the context of hazard mitigation study a comprehensive approach is then necessary through careful handling on problems associated with 'front- (hulu) and end- (hilir)' user treatment and other relevant aspects as well. In the perspective of end-user treatment, information about the generation of tsunamimagnetic signals and magnetic anomaly could possibly be incorporated into school curricula through relevant educational and laboratory activities (Prastowo \& Ain, 2015), and classroom activities on the basis of SETS and local wisdom (Rusilowati, Supriyadi, \& Widiyatmoko, 2015). A combined approach of both types of treatment through integrated science in a classroom setting could also be implemented by providing students with discussions on mangrove plantation along a shoreline that is able to reduce ocean current and incoming wave energy hence to protect population living nearby (Kristiyanto, Armono, \& Soemarno, 2013). In prinpicle, efforts in reducing disaster risks to minimum are thus compulsory for all authorities including educators, scientists, engineers, and decision makers to do the best for minimizing risks of disaster dan maximizing awareness of disaster-related science (Suppassri et al., 2015).

\section{CONCLUSIONS}

Tsunami waves caused by large earthquakes with the hypocenter located below the sea surface generate secondary magnetic signals hence anomalies observed as small perturbations on the primary, Earth's magnetic fields. In this study, the secondary fields are then decomposed into the vertical $b_{z}$ and horizontal $b_{\mathrm{H}}$ components and determined by analytical and visual estimates. Theoretical estimates of the two components depend on two interconnected parameters: $h / L$ and $c / c_{s}$. If $h / L$ $\geq 2.0$ and $c / c_{\mathrm{s}} \approx 1$ hold (deep-sea cases with ignorable diffusion effects), then $b_{z}$ is calculated using frozen-flux approximation. Using this approximation, estimate of $b_{z}$ yields $b_{z}=0.43$ $\mathrm{nT}$ for the 2010 Chilean event and $b_{z}=15.31$ nT for the 2011 Tohoku occurrence. Values of $b_{z}$ found for the two large tsunamis are in good agreement with magnetogram from both INTERMAGNET and BCMT, where $b_{z}=0.47 \mathrm{nT}$ for the 2010 Chilean case and $b_{z}=15.80 \mathrm{nT}$ for the 2011 Tohoku tsunami. Another important result is that the horizontal signal $b_{H}$ reaches at its maximum peak at about 2.5 minutes before the vertical signal $b_{\mathrm{z}}$ does.

The 2010 Mentawai event occurred in a relatively shallow water and is unique in that the roles of diffusion effects become into play. Some observational points show a large deviation of $b_{z}$ estimates from the expected values, suggesting that prediction of $b_{z}$ based on the frozen-flux theory is inapplicable to cases where oceanic diffusion is strong. However, the scatter of the calculated value for $b_{z}$ in the ran-

ge of $b_{z} \leq 2.5 \mathrm{nT}$ for this case is consistent with $b_{z} \sim 2 \mathrm{nT}$ recorded by magnetogram from INTERMAGNET and BCMT for the 2004 Aceh tsunami.

Monitoring of magnetic signals and anomalies due to tsunami can therefore be a candidate for tsunami early warning to assign a more comprehensive system in cooperation with the existing method based on seismic signal processing and monitoring. Good estimates of $b_{\mathrm{z}}$ and $b_{\mathrm{H}}$, in agreement with prediction by visual inspection on magnetogram and the results from relevant previous work, however, have not yet unrevealed the characteristic of tsunami wave propagation. Issues, such as tsunami height when approaching the shoreline, tsunami propagation direction and its associated speed at open seas remain important and therefore such issues become challenging for future work.

\section{ACKNOWLEDGEMENTS}

The authors would like to thank anonymous reviewer(s) of JPFI UNNES for their best suggestion and invaluable comments upon this article from a simple form of a submitted version to a high level of a reviewed article ready for publication. TP and LC also thank the Editor in Chief of JPFI for the hospitality during the completion of the work.

\section{REFERENCES}

BCMT (2016). Data Plot. http://www.bcmt.fr/data plot.php. Accessed on 20-21 April 2016.

Blewitt, G., Kreemer, C., Hammond, W.C., Plag, H., \& Stein, S. (2006). Rapid determination of earthquake magnitude using GPS for tsunami 
warning systems. Geophysical Research Letters, 33, 1-4.

IAGA (2016). Model field at a point by IGRF (IGRF12). International Geomagnetic Reference Field/World Data Centre (IGRF/WDC) https:// www.ngdc.noaa.gov/lAGA/vmod/igrf.html linked to http://wdc.kugi.kyoto-u.ac.jp/igrf/ point/index.html. Accessed on 27 March 2016 and 18 April 2016.

Ichihara, H., Hamano, Y., Baba, K., \& Kasaya, T. (2013). Tsunami source of the 2011 Tohoku earthquake detected by an ocean-bottom magnetometer. Earth and Planetary Science Letters, 382, 117-124.

INTERMAGNET (2016). Data-Plotting Service. http:// www.intermagnet.org/data-donnee/dataploteng.php?type=xyz. Accessed on 20-21 April 2016.

Klausner, V., Domingues, M. O., Mendes, O., \& Papa, A. R. R. (2011). Tsunami effects on the $\mathrm{Z}$ component of the geomagnetic field. August 25,2011 . physics.space-ph physics.aoph arXiv:1108.4893v1.

Klausner, V., Kherani, E. A., \& Muella, M. T. A. H. (2016). Near- and far-field tsunamigenic effects on the $Z$ component of the geomagnetic field during the Japanese event, 2011. Journal of Geophysical Research, 121, 1772-1779.

Kristiyanto, A., Armono, H. D., \& Soemarno. (2013). Kemampuan hutan mangrove rumpun Rhizhophora SP dan Avicennia SP dalam meredam gelombang laut. Jurnal Pendidikan Fisika Indonesia, 9(2), 173-183.

Madlazim \& Prastowo, T. (2016). Evaluation of earthquake parameters used in the Indonesian tsunami early warning system. Earthquake Science, 29(1), 27-33.

Manoj, C., Maus, S., \& Chulliat, A. (2011). Observation of magnetic fields generated by tsunamis. EOS, 92(2), January 11, 2011, 13-14.

Minami, T., \& Toh, H. (2013). Two-dimensional simulations of the tsunami dynamo effect using the finite element method. Geophysical Research Letters, 40, 4560-4564.

Minami, T., Toh, H., \& Tyler, R. H. (2015). Properties of electromagnetic fields generated by tsunami first arrivals: classification based on the ocean depth. Geophysical Research Letters, 42, 2171-2178

NGDC (2016). Bathymetric Data Viewer. National Centers For Environmental Information/ National Geophysical Data Center (NCEI/NGDC) https://maps.ngdc.noaa.gov/viewers/bathymetry/. Accessed on 27 March 2016 and 18 April 2016.

NOAA (2016). Recent and Historical Tsunami Events and Relevant Data. Pacific Marine Environmental Laboratory/National Oceanic and Atmospheric Administration (PMEL/NOAA) http://nctr.pmel.noaa.gov/database_devel. html. Accessed on 27 March 2016 and 18 April 2016.

Prastowo, T. \& Ain, T. N. (2015). Percobaan gravity current untuk menguji konsep hidrodinamika dan hukum kekekalan massa pada fluida inkompresibel. Jurnal Pendidikan Fisika Indonesia, 11(1), 84-92.

Prastowo, T., \& Jannah, A. (2015). Estimates of the earth's liquid outer core velocity using toroidal assumption and the DGRF/IGRF 1990-2000 magnetic models. Proceedings of International Conference on Science and Science Education (IConSSE), Faculty of Science and Mathematics (FSM), Satya Wacana Christian University (SWCU), August 1, 2015.

Rusilowati, A., Supriyadi, A., \& Widiyatmoko. (2015). Pembelajaran kebencanaan alam bervisi SETS terintegrasi dalam mata pelajaran Fisika berbasis kearifan lokal. Jurnal Pendidikan Fisika Indonesia, 11(1), 42-48.

Santosa, B. J. (2012). Seismogram analysis of earthquakes in Sumatra-Java at HYB observatory station. Jurnal Pendidikan Fisika Indonesia, 8(2), 195-202.

Satake, K. (2014). Advances in earthquake and tsunami sciences and disaster risk reduction since the 2004 Indian ocean tsunami. Geoscience Letters, 1(15), 1-13.

Satriano, C., Wu, Y. M., Zollo, A., \& Kanamori, H. (2011). Earthquake early warning: concepts, methods, and physical grounds. Soil Dynamics and Earthquake Engineering, doi:10.1016/j. soildyn.2010.07.007.

Sugioka, H., Hamano, Y., Baba, K., Kasaya, T., Tada, N., \& Suetsugu, D. (2014). Tsunami: ocean dynamo generator. Scientific Report on www. nature.com. 4: 3596, 1-7.

Suppasri, A., Goto, K., Muhari, A., Ranasinghe, P., Riyaz, M., Affan, M., Mas, E., Yasuda, M., \& Imamura, F. (2015). A decade after the 2004 Indian Ocean Tsunami: the progress in disaster preparedness and future challenges in Indonesia, Sri Lanka, Thailand and Maldives. Pure and Applied Geophysics, 172, 33133341.

Tatehata, H., Ichihara, H., \& Hamano, Y. (2015). Tsunami-induced magnetic fields detected at Chichijima Island before the arrival of the 2011 Tohoku earthquake tsunami. Earth, Planets and Space, 67, 185-195.

Tyler, R. H. (2001). On the theory of magnetic fields generated by planetary oceans, Proceedings of The Third Conference on Marine Electrodynamics (MARELEC), Spearhead Exhib. Stockholm, Sweden.

Tyler, R. H. (2005). A simple formula for estimating the magnetic field generated by tsunami flow. Geophysical Research Letters, 32, L09608, 1-4.

Wang, B., \& Liu, H. (2013). Space-time behaviour of magnetic anomalies induced by tsunami waves in open ocean. Proceedings of The Royal Society A. 469, 1-17.

Zhang, L., Baba, K., Liang, P., Shimizu, H., \& Utada, H. (2014). The 2011 Tohoku tsunami observed by an array of ocean bottom electromagnetometers. Geophysical Research Letters, 41, 1-9. 